\title{
VERIFICAÇÃO DE REGRAS EM MODELOS BIM: UM ESTUDO DE CASO SOBRE PROJETO DE ARQUITETURA DE ESTAÇÕES METROVIÁRIAS ${ }^{1}$
}

\author{
BIM CODE-CHECKING: A CASE STUDY OF METRO ARCHITECTURAL \\ PROJECTS
}

\author{
Antonio Ivo de B. Mainardi Neto \\ Universidade de São Paulo (USP) \\ ivomainardi@usp.br \\ Eduardo Toledo Santos \\ Universidade de São Paulo (USP) \\ etoledo@usp.br
}

\begin{abstract}
Resumo
A adoção da Modelagem da Informação da Construção (BIM) pela indústria da construção trouxe novos processos e usos, dentre eles a Verificação de Regras. Esta operação integra o processo de análise e aprovação de projetos, onde normas, leis e códigos são transformados em regras configuradas em um software especializado, possibilitando a verificação automatizada do seu atendimento no modelo BIM, com a geração de um relatório de conformidade. Este processo permite ganhos em tempo e precisão, já que o analista pode focarse apenas nos resultados de não conformidade. Para que a Verificação de Regras seja efetiva, é necessário verificar se plataforma escolhida atende aos tipos de regra necessários. Deve-se também verificar se a criação do modelo BIM foi realizada corretamente e se contém todas as informações necessárias. Este artigo analisará o processo de Verificação de Regras, detalhando cada etapa. Regras para projetos de estação metroferroviárias serão utilizadas como estudo de caso. O aplicativo Solibri Model Checker (SMC) foi escolhido como plataforma para a verificação de regras e as regras aplicadas ao estudo de caso são classificadas conforme suas características e adequação para implementação no SMC. Em seguida, serão implementadas e validadas com um projeto real em BIM.
\end{abstract}

Palavras-chave: BIM. Verificação de regras. Metrô.

\begin{abstract}
The adoption of Building Information Modeling by the construction industry allows new processes to be implemented along with the many BIM uses. One of these is "code checking". This BIM use is to be integrated in the process of analysis and approval of projects. It includes a phase where laws and/or codes are transformed into rules coded into software, enabling verification of rule conformance and noncompliance reporting. This process can yield gains in time and accuracy, since the analyst can focus only on the results of the noncompliance report. To be effective, code-checking requires verifying if the chosen platform supports the needed rule types. Also, care must be taken to assure that the BIM model was correctly created and contains all
\end{abstract}

\footnotetext{
${ }^{1}$ MAINARDI NETO, A. I. B.; SANTOS, E. T. Verificação de Regras em Modelos BIM: Um estudo de caso sobre projeto de arquitetura de estações metroviárias. In: ENCONTRO BRASILEIRO DE TECNOLOGIA DE INFORMAÇÃO E COMUNICAÇÃO NA CONSTRUÇÃO, 7., 2015, Recife. Anais... Porto Alegre: ANTAC, 2015.
} 
need data. In this paper, the code-checking process is analyzed, detailing each of its steps. Rules for the architectural design of subway stations are used as a case study. Solibri Model Checker (SMC) was chosen as the base platform for code-checking and the rules for the case study are classified according to its characteristics and suitability for implementation in SMC. Then, they were implemented and validated with a real design in BIM.

Keywords: BIM. Code-checking. Metro. Subway.

\section{INTRODUÇÃO}

Uma estação metroferroviária passa por diversas etapas com projetos, obras, orçamentos e outros, seja um novo empreendimento, um retrofit ou quando de sua manutenção e operação. A etapa de projeto é onde tudo é possível, onde arquitetos e engenheiros desenvolvem suas técnicas para entregar o melhor produto, para que a obra ocorra com a menor interferência tanto em seu desenvolvimento e instalação, como no seu cronograma e custo. A utilização do BIM (Building Information Modeling / Modelagem da Informação da Construção) na construção civil é guiada por objetivos, sendo que para cada edificação ou empresa, são determinados quais objetivos se pretende alcançar. Um dos pontos primários do BIM é a melhoria na etapa de projeto, já que a edificação estará representada em três dimensões, melhorando assim a precisão de dimensionamentos, visualização, acesso a uma fonte de informações única, confiabilidade de compatibilização entre todas as disciplinas, dentre outros benefícios.

Assim como em outras empresas públicas brasileiras, o Metrô de São Paulo realiza licitações públicas para o desenvolvimento de projetos civis, que passam pela análise de técnicos internos, gerando revisões até sua aprovação final. A partir de novembro de 2013 o Metrô-SP licita seus projetos utilizando o processo BIM para atingir incialmente os objetivos de melhoria na compatibilização e quantificação, além da análise de projetos em 3D possibilitando a visualização do projeto completo e não apenas desenhos. São requeridos projetos básicos em BIM para as disciplinas de Arquitetura, Estrutura, Hidráulica, Geotecnia e via permanente, sendo este artigo focado no projeto de Arquitetura.

Cada projeto passa pela análise interna onde os técnicos e profissionais avaliam as informações, produzindo comentários para ajustes. Estes seguem para o projetista que avaliará o atendimento aos comentários emitindo uma nova revisão. Este ciclo se repete até a aprovação final. A cada revisão, o processo de análise e possível aprovação do projeto consome em média 25 dias para a primeira e 15 dias para as demais revisões ${ }^{2}$, alcançando a média de 4 revisões por projeto. Com o intuito de melhorar e diminuir o tempo empregado nas análises, além de revisões em aspectos como cronograma e contratos, está sendo feita a implementação de um processo de análise automatizada utilizando as informações providas pelo projeto em BIM, que neste trabalho, denominaremos Verificação de Regras ou Code-checking (PENNSYLVANIA STATE UNIVERSITY, 2012) / Consistency check (STATSBYGG, 2013).

\section{A VERIFICAÇÃO DE REGRAS}

A Verificação de regras é definida por Eastman et al. (2009) como a análise do projeto através das informações dos componentes, suas relações e atributos. A Verificação de regras faz parte do processo de análise com objetivos como padronizar a análise e diminuir o tempo necessário nesta etapa. O desenvolvimento e aplicação deste uso datam há mais de 20 anos (NAWARI, 2012b) e, inicialmente, utilizavam-se informações de projetos planificados por meio de arquivos digitais com vetores em 2D, como o caso de Singapura

\footnotetext{
2 Valor verificado nos últimos 3 projetos e indicado em contrato, podendo variar.
} 
iniciado em 1995 (KHEMLANI, 2005). Com o surgimento do BIM, este uso recebeu um novo impulso e atualmente é tema de inúmeras pesquisas, artigos e publicações.

Khemlani (2005) menciona a vantagem que o uso do BIM tem em relação ao CAD, com habilidades para dar suporte a análises e validação do projeto. A autora comenta também que o processo de análise e aprovação manual, como é realizado atualmente por grande parte do mercado, requer um trabalho muito intenso e demorado, com grandes chances de inconsistências devido às possíveis diferentes interpretações do analista, além da constante falta de tempo para esta etapa.

\subsection{Classificação das Regras}

A identificação das regras e classificação em classes serve não apenas para registro, mas para facilitar o entendimento e aproveitamento de aplicações já realizadas, além de apontar aos desenvolvedores de plataformas quais são as necessidades para um uso pleno. Este artigo utilizará esta classificação, e não tem a intenção de discutir seus algoritmos ou como as plataformas devem funcionar. Solihin e Eastman (2015) apresentam quatro classes de regras:

Classe 1 - Regras que necessitam de poucos dados. A verificação utilizará informações existentes nos componentes, como dados presentes em parâmetros. Exemplo desta classe é a verificação se há a informação do código do componente conforme a padronização de classificação;

Classe 2 - Regras que necessitam de um valor derivado simples, como geometria, utilizando-a para a verificação. Um exemplo disto é a verificação de espaçamento entre dois objetos, onde a informação não está contida no componente, utilizando-se da geometria como referência;

Classe 3 - Regras que necessitam de uma estrutura complexa de dados, onde o software utilizará dados geométricos, topológicos, propriedades e possivelmente algoritmos para verificação. Um exemplo desta classe é a análise de distribuição de detectores de fumaça onde é necessária uma triangulação e criação de um mapa de cobertura para saber se todo o ambiente está coberto. Segundo o autor, a plataforma que alcançou esse tipo de classe é o FORNAX;

Classe 4 - Regras que sugerem uma solução. Utilizando o mesmo exemplo da classe 3 , a má distribuição resultará em um aviso e, na classe 4, a plataforma é capaz de sugerir resoluções ao projetista.

Nawari (2012b) também aponta como crucial a identificação das limitações das plataformas de verificação e a indicação clara de quais partes das leis, normas e diretrizes não foram capazes de atender. Solihin e Eastman (2015) citam um desafio para a Verificação de regras - a identificação de falso positivo - que, ao contrário de um falso negativo que é apontado no relatório e analisado, não é listado no relatório e, portanto, não pode ser identificado pelo analista, necessitando um cuidado especial na criação das regras para que omitam apenas os verdadeiramente positivos.

\subsection{As plataformas de verificação}

As regras são criadas conforme a plataforma escolhida, podendo ser um plug-in aplicado a um software de projetos, uma plataforma baseada na web utilizando-se o navegador ou um software de computador específico a este uso (EASTMAN et al., 2009). Como algumas empresas contêm limitações com acessos e uso de aplicações web, e o profissional que 
analisa o projeto normalmente não é o mesmo que o produz, este artigo focará no uso de um software específico para a Verificação de regras.

Com este cenário, Eastman et al. (2009) obteve acesso a algumas das plataformas mais comuns utilizadas, conforme Tabela 1. O FORNAX e o EDM são plataformas com grande potencial para a configuração das regras, porém, como necessitam de programação para a criação das mesmas, sua utilização fica limitada a quem tem esse conhecimento. O SMC Solibri Model Checker está presente na maior parte dos casos apresentados por Eastman et al. (2009). Sua interface gráfica o torna mais acessível e assim alcança um maior número de profissionais e, consequentemente, é mais frequentemente atualizado. Este artigo apresenta o uso do SMC em seus casos.

Tabela 1: Exemplos de aplicação de Verificação de Regras e plataformas utilizadas

\begin{tabular}{|l|l|l|l|l|l|}
\hline $\begin{array}{l}\text { País, Agência de } \\
\text { desenvolvimento }\end{array}$ & $\begin{array}{l}\text { Singapura, } \\
\text { CORENET }\end{array}$ & $\begin{array}{l}\text { Noruega, } \\
\text { Statsbygg }\end{array}$ & $\begin{array}{l}\text { Austrália, CRC } \\
\text { para Cl }\end{array}$ & $\begin{array}{l}\text { EUA, } \\
\text { ICC }\end{array}$ & EUA, GSA \\
\hline $\begin{array}{l}\text { Objetivo das } \\
\text { regras }\end{array}$ & $\begin{array}{l}\text { Código de } \\
\text { obras }\end{array}$ & Acessibilidade & Acessibilidade & $\begin{array}{l}\text { Código } \\
\text { de obras }\end{array}$ & $\begin{array}{l}\text { Circulação/ } \\
\text { Segurança }\end{array}$ \\
\hline Plataforma & FORNAX & SMC & EDM & SMC & SMC \\
\hline \multicolumn{7}{|c|}{ Fonte: Adaptado de Eastman et al., 2009. } \\
\hline
\end{tabular}

\subsection{IFC - Industry Foundation Classes}

Com o surgimento do Industry Foundation Classes (IFC) nos anos 1990 (NAWARI, 2012a), as possibilidades e alcances com a Verificação de Regras foram impulsionados. Se antes o uso das informações contidas no modelo $3 \mathrm{D}$ só era possível através de arquivos nativos, onde não havia integração entre projetos originados de diferentes softwares, com o IFC esse bloqueio deixa de existir, já que sua estrutura é baseada em código aberto, permitindo que o mesmo arquivo contendo o modelo 3D possa ser utilizado em softwares de diferentes desenvolvedores, permitindo também que cada projetista desenvolva o projeto em software de sua preferência. Em outra plataforma, esses arquivos são unificados representando a construção finalizada, com todos os projetos em um só, permitindo assim que as regras escritas para a Verificação de Regras possam ser aplicadas a todos os projetos, independente do software de origem. Apesar de o IFC ter impulsionado o uso de Verificação de Regras, Nawari (2012a) cita a necessidade de receber um reforço do nível da lógica, visto que suas especificações não estão embasadas em uma lógica formal, o que melhoraria assim as possibilidades dos sistemas de Verificação de Regras.

\subsection{Padronização}

Nawari (2012b) aponta a importância da organização dos componentes em categorias e subcategorias em uma hierarquia taxonômica, já que muitos dos processos de Verificação de Regras, em um primeiro momento, filtram a categoria e subcategorias para, após isso, aplicar a regra. A Associação Brasileira de Normas Técnicas (ABNT), por meio da Comissão de Estudo Especial de Modelagem de Informação da Construção (CEE-134) está desenvolvendo a NBR 15965 (Sistema de classificação da informação da construção), apresentando um padrão de classificação hierárquica de componentes como defendido por Nawari (2012b), com categorias e subcategorias. Isso facilitará o primeiro estágio de verificação, além de permitir que cada regra aprofunde a necessidade da informação, como selecionar todas as portas, indo até o nível 2, ou somente as de madeira, indo até o nível 3.

"Regras inteligentes são referidas como o formato digital informatizado das regras de edificação que permitem a checagem de regulamentações e regras de modo automatizado sem a necessidade de alterar o projeto, sendo preferível que a análise do projeto seja 
realizada com base na configuração de componentes paramétricos, suas relações e atributos" (NAWARI, 2012a, p. 943). As regras programadas buscarão dados em campos e configurações pré-programadas que, se não forem localizadas, resultarão em erro.

Além da padronização da identificação dos componentes, é importante determinar e identificar quais informações serão necessárias para a aplicação das regras e em qual parâmetro deve estar localizado. Solihin e Eastman (2015) apontam dois aspectos relacionados com a Verificação de regras: o LOD - Level of Development e o MVD - Model View Definition. O MVD (HIETANEN, 2008) é um padrão definido pela buildingSmart que tem como base o IFC (Industry Foundation Classes). Os MVDs servem como um acordo entre as partes, por exemplo, o projetista e o contratante, onde estão incluídos como, quais e onde devem estar as informações para determinado intercâmbio, sendo assim um padrão utilizado em diversos momentos e aplicações no projeto.

O LOD foi documentado pelo BIM Forum (2013) com o objetivo de criar um critério padronizado sobre os níveis de desenvolvimento do modelo BIM. Esses níveis devem constar do contrato ou de um plano de execução onde todos os envolvidos saibam até qual nível o modelo deve estar desenvolvido em cada etapa do projeto. Por exemplo, em um momento inicial não há a necessidade de ter os detalhamentos da fixação de estrutura metálica, podendo ser desenvolvido posteriormente. Para projetos básicos civis do Metrô de São Paulo compreende-se que o LOD não se aplica, em cada contrato está definido o que deve ser desenvolvido, podendo a primeira revisão do projeto já ser aprovada, não havendo a necessidade de definição do que deve ser entregue por etapas.

Além do padrão de informações e dados, é essencial que seja padronizado como o modelo deve ser desenvolvido, sua organização de pavimentos, onde devem se referenciar (osso ou acabado), se laje e acabamento devem ser geometrias separadas, se o acabamento do piso deve ser dividido por ambiente. A Figura 1 ilustra um problema que impacta a Verificação de Regras: está representado o piso de plataforma de uma estação modelada como uma peça única. Esta tipologia de estação compreende um poço central alinhado ao túnel, portanto o piso é alargado na parte central da extensão da plataforma. O aplicativo de verificação identifica a geometria com seus limites através de um retângulo, não permitindo a identificação de espessura apenas da plataforma, sendo necessário indicar ao projetista que os pisos devem ser divididos por função, como túnel e poço, permitindo que a regra seja aplicada. Estas informações devem estar contidas em um documento entregue ao projetista no início do projeto.

Figura 1 - Diferenças na interpretação da geometria para aplicação de regra

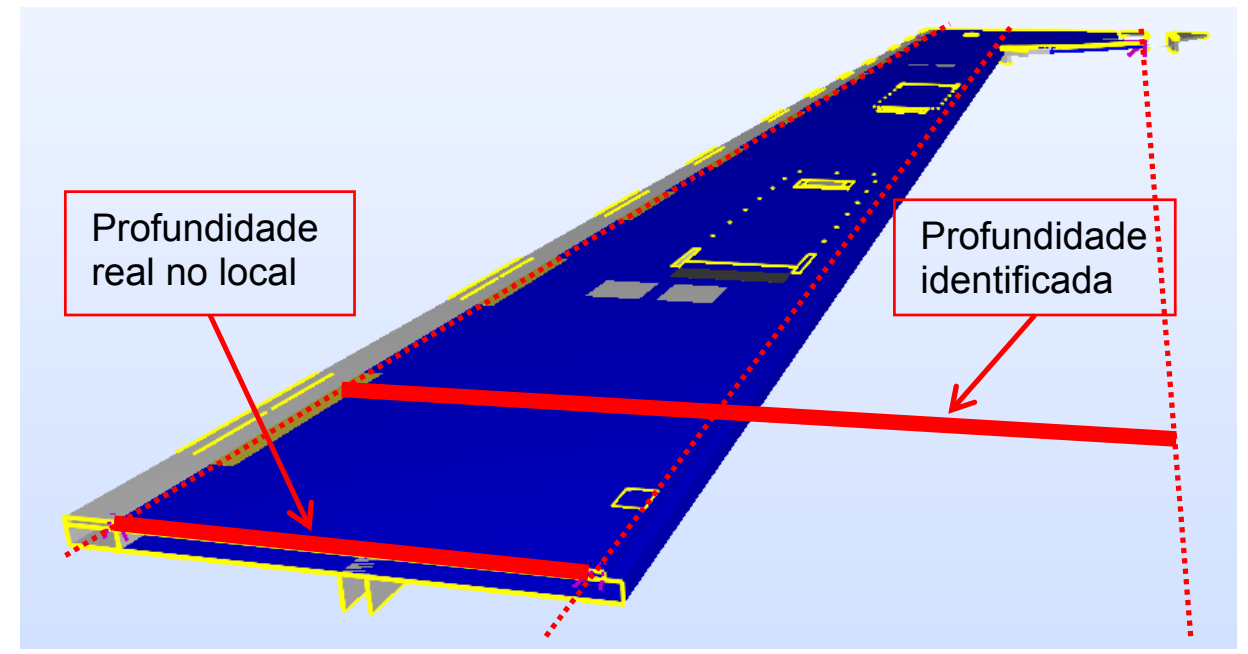

Fonte: Autor, 2015 


\section{O PROCESSO DA VERIFICAÇÃO DE REGRAS}

O processo de análise tradicional, utilizando desenhos em 2D, utiliza basicamente os conhecimentos prévios do profissional baseados em técnicas, normas, leis e experiências que, por meios visuais, verifica o projeto (NAWARI, 2012a). Apesar de o analista ser experiente e com alto grau de conhecimento, mesmo com os esforços da empresa em proporcionar um nivelamento entre seus analistas e a existência padronização que facilita a análise, não se pode esperar que todos tenham os mesmos critérios para analisar todos os projetos. Mesmo assim, Nawari (2012a) expõe as vantagens do ser humano nesta etapa, com sua facilidade de interpretação e busca por alternativas, tornando-o insubstituível.

Porém, o computador tem grande velocidade de processamento das informações, tornandose mais rápido que o humano em algumas aplicações (NAWARI, 2012b). Portanto, a profissão de analista não deve ser substituída pelo computador, mas sim acrescida de novos processos e procedimentos a fim de aumentar seu desempenho e padronização. Para que este processo seja bem sucedido, Eastman et al. (2009) citam quatro etapas necessárias: Interpretação das regras, Preparação do modelo, Execução da regra e Relatório de resultados conforme a Figura 2.

Figura 2 - Etapas do processo de Verificação de Regras

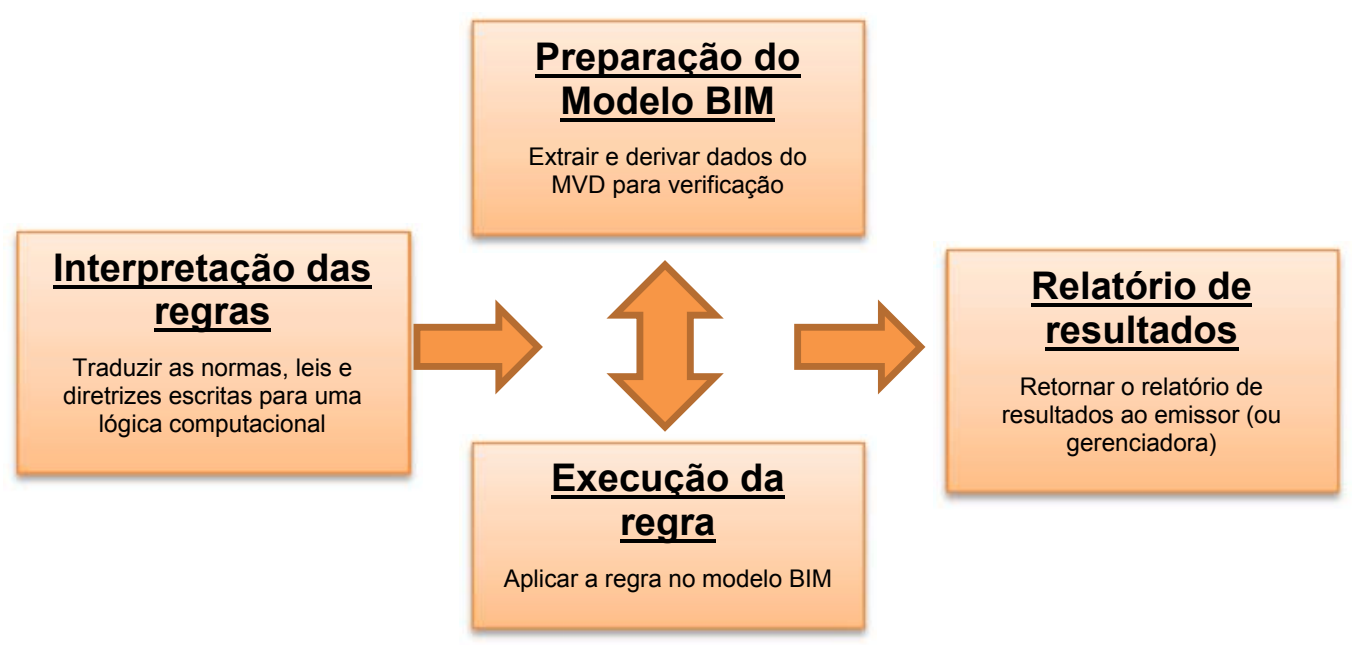

Fonte: Adaptado de Eastman et al. (2009)

\subsection{Interpretação da regra}

Normas e leis atuais foram escritas por humanos contando com a interpretação que o cérebro é capaz, e as soluções e plataformas para aplicação da Verificação de regras atualmente não permitem o entendimento de interpretações, havendo assim uma limitação na aplicação direta das regras ao computador. Há, então, a necessidade de uma etapa para a tradução das regras de uma maneira que o computador, utilizando uma plataforma, possa entender, processar e ser utilizado para este tipo de análise. Nawari (2012) e Eastman et al. (2009) citam que pela dificuldade de tradução, há a necessidade de algumas regras se subdividirem e outras serem reescritas.

\subsection{Preparação do modelo}

A preparação do modelo é a etapa que relaciona as regras interpretadas com a execução da análise. As regras configuradas na plataforma analisam informações geométricas e não geométricas. Portanto, são informações que o projetista adicionou ao componente ou 
projeto. Para que seja possível sua verificação é necessário checar se as informações desejadas estão presentes e na formatação correta. É de extrema importância que quem fará a análise, seja o contratante ou não, no momento inicial do projeto documente e repasse para o projetista quais serão os dados utilizados no processo e sua formatação. Muitas dessas informações são extremamente complicadas de serem adicionadas em um momento posterior, sendo que algumas delas alteram a forma como se realiza a modelagem.

Deve-se pensar na possibilidade de trabalhar com mais de um modelo e com um software de projeto possibilite a exportação de arquivos IFC com usos diferentes, derivados de um ou mais arquivos do projeto. Han apud Eastman et al. (2009) propõe o uso de modelos separados, contendo apenas as informações necessárias para um tipo específico de Verificação de Regra, resultando em maior eficiência na execução da verificação.

\subsection{Execução da regra}

Eastman et al. (2009) apontam a necessidade de um processo nomeado "Pré-verificação sintática da vista de modelo". Este processo irá analisar se as informações necessárias para outras análises como nomenclatura e código do componente estão contidas em suas propriedades. Além de verificar se todas as informações existem no modelo, a sua integridade também deve ser verificada em um processo prévio. Os resultados obtidos não contemplam suposições ou interpretações, portanto a assertividade do resultado corre risco se a informação presente não estiver correta. Sobreposição e duplicação de componentes resultam em problemas na integridade do modelo e da informação. A Verificação de Regras ainda será realizada ao mesmo tempo de maneira automatizada (computador) e manual, ambas se complementando, isso devido ao processo de implantação, existência de regras prontas e maturidade de normas e leis para sua aplicação (EASTMAN et al., 2009). As regras criadas podem ser utilizadas pelo projetista para analisar seu projeto antes da entrega, diminuindo a quantidade de comentários e revisões.

\subsection{Relatório de resultados}

A última etapa da Verificação de Regras contempla o relatório de verificação, o qual contém o resultado dos processos anteriores. Segundo Eastman et al. (2009), enquanto edifícios têm claras definições e divisões como níveis e ambientes, muitas verificações utilizarão contextos que não pertencem a uma ontologia lógica, tornando difícil o simples ato de representar o erro. Componentes como vigas e paredes, por exemplo, apresentam informação clara a qual nível pertencem, porém, outros componentes, como um montante pertencente a um caixilho, não contêm a informação de nível pois é parte integrante do caixilho, dificultando um relatório que utilize o nível como referência de localização. Podemos identificar este montante por meio das coordenadas e também é possível mover a câmera (visão apresentada no computador do modelo tridimensional) para ele, demonstrando visualmente o componente. $O$ relatório pode se apresentar sob a forma de um arquivo BCF (BIM Collaboration Format) que, ao ser carregado no software de desenvolvimento de projeto, indica exatamente as não conformidades, tornando o processo de revisão mais ágil.

\section{ESTUDO DE CASO: VERIFICAÇÃO DE REGRAS EM PROJETOS METROVIÁRIOS}

As regras simuladas neste artigo partem de um documento nomeado "Instrução de Projeto Básico de Arquitetura", presente nos editais de licitação para o desenvolvimento de projetos 
básicos civis para o Metrô de São Paulo. As regras seguem a classificação proposta por Solihin e Eastman (2015), sendo a plataforma utilizada o SMC (Solibri Model Checker).

A Figura 3 representa o fluxo de trabalho para a criação e aplicação das regras. Seguindo este fluxo, é possível identificar se a plataforma tem capacidade de atender a regra, desde a existência da informação ou de regra-padrão até a necessidade de criar outras geometrias ou modelos para a análise.

Figura 3 - Fluxograma para criação de regras

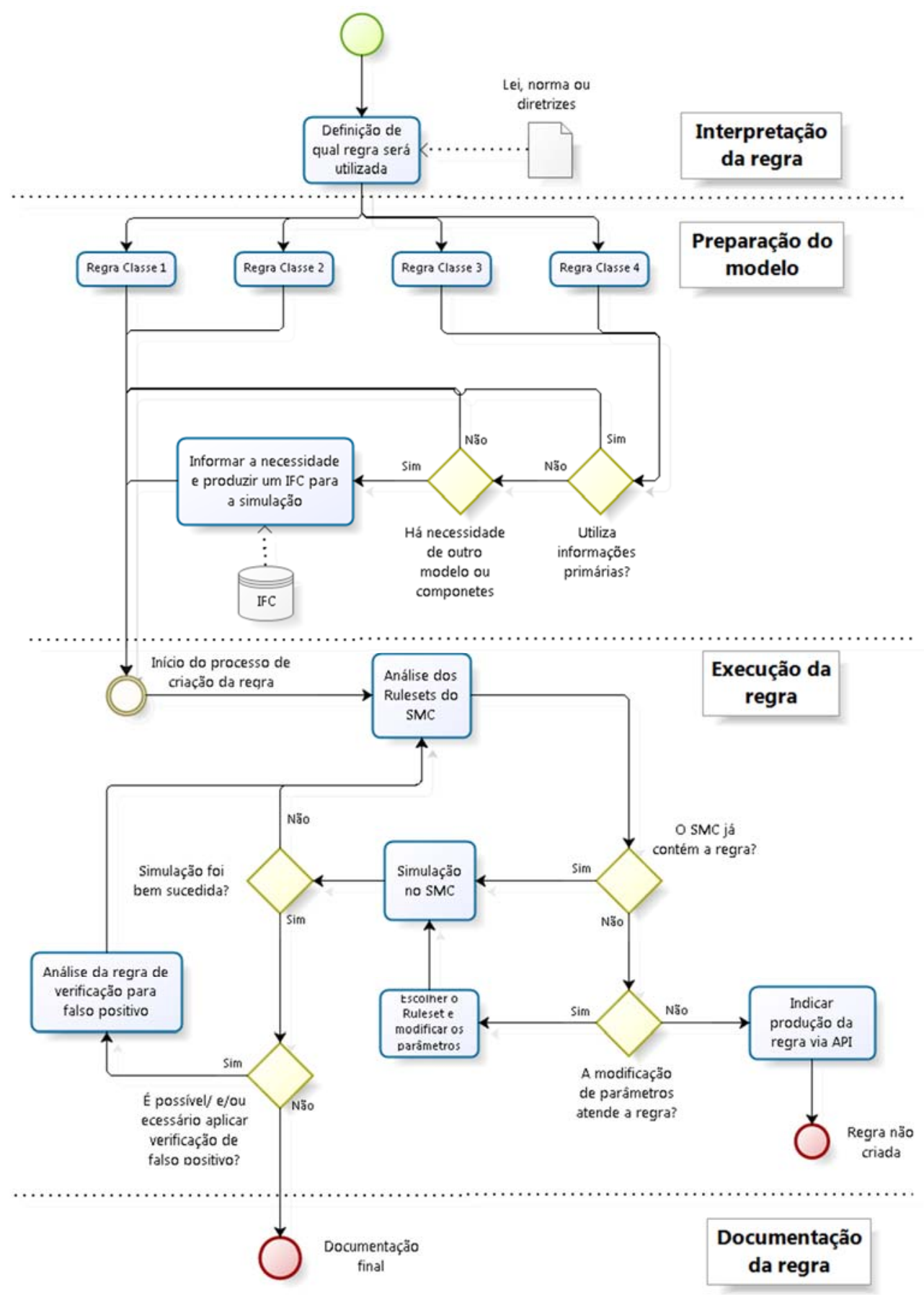

Fonte: Autor (2015) 
No SMC já constam diversas regras pré-configuradas, que chamaremos de regras-padrão, onde as informações como parâmetros e componentes que serão verificados são editáveis. Portanto, as regras apresentadas baseiam-se em modificações de outras existentes. O SMC também é capaz de analisar parte das regras de classe 3 porém, assim como apontado por Solihin e Eastman (2015), o FORNAX é a plataforma que atende melhor as análises do nível desta classe. Somado a isto, o documento utilizado como base de regras para este artigo não contém regras de classe 3 e 4 . Portanto, o estudo de caso utilizará somente regras das classes 1 e 2 . Será apresentada apenas uma regra de cada tipo para ilustrar sua aplicação.

\subsection{Regra 1}

Classe 1 Todos os componentes deverão conter o código do componente conforme ABNT-15965

Para que seja seja possível executar a Verificação de Regras, é necessário incialmente identificar os componentes relacionados a esta regra. Para esta identificação, naturalmente é utilizado a informação de categoria como portas, janelas e paredes, porém nos softwares de projeto alguns componentes não se encaixam nas categorias existentes. Exemplo disto é a escada rolante que, apesar de ser um equipamente mecânico, deve ser submetida às regras de escadas. Para facilitar e melhorar este processo de identificação, não apenas para este uso de Verificação de Regras, é indicada a utilização de um padrão de classificação como citado no item 2.4.

Esta regra pode ser considerada como uma pré verificação, já que outras regras utilizarão a classificação da norma ABNT NBR 15965 (2011), analizando se todos os componentes estão com a informação preenchida, sendo sua veracidade verificada em outra regra. Para esta regra foi utilizada a regra da biblioteca do SMC denominada "Property Rule template with component filters" (Fonte: Autor (2015) 4), onde, no primeiro quadro, foi configurado para incluir todos os componentes do arquivo e excluir vigas e pilares, já que o foco é arquitetura. No segundo quadro, a condição da regra é verificar se a propriedade "Código Metrô" contém alguma informação. O resultado desta regra é o relatório de componentes sem a informação de classificação, impedindo a execução de outras regras.

Figura 4 - Interface de configuração da regra

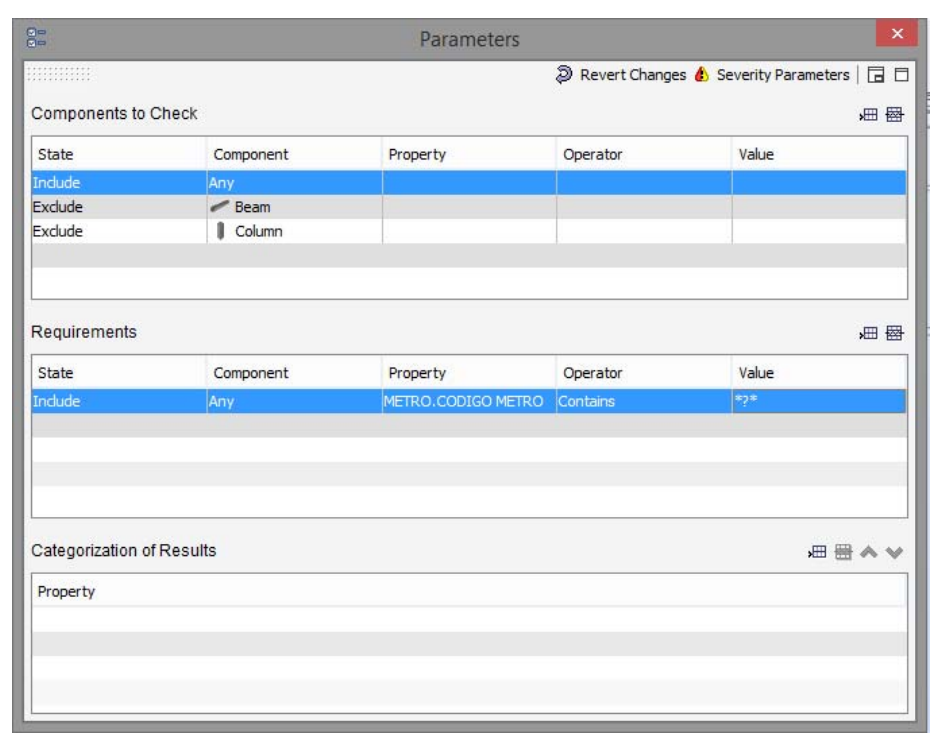

Fonte: Autor (2015) 


\subsection{Regra 2} acomodação com comprimento mínimo de 1,5 vezes a largura do conjunto de escadas e/ou rampas.

A regra padrão do SMC utilizada foi "Free area in front of components", onde é possível indicar quais componentes devem ser verificados, a profundidade de área livre e tolerância lateral e a direção de verificação. Conforme a Figura 5, no primeiro quadro são indicados os componentes que devem ser checados - neste caso a escada, a rampa e a escada rolante. Os dois primeiros têm sua própria categoria, mas a escada rolante não tem categoria própria. Para evitar esse problema, é utilizado um padrão de classificação indicado em contrato (item 2.4), neste caso a ABNT NBR 15965 (2011). Esta norma apresenta o grupo "escadarias", como patamares e escadas, identificado pelo código 3E.41.31.13. Este código contempla todos os componentes que compõem escadarias e/ou rampas sendo que, para especificá-los, seria utilizada a $5^{a}$ coluna, substituindo a necessidade de identificação por categorias. É importante enfatizar a importância da pré-verificação a todos os componentes como indicado na regra 1 (item 4.1). O valor que será verificado de área livre nas extremidades das escadas, depende de um cálculo que utiliza informação derivada do componente. Esta opção de cálculo não é permitida nas regras da biblioteca do SMC, portanto adotou-se o padrão de 3,00 metros, uma vez que a largura mínima de circulação indicada para este tipo de projeto é 2,00 metros.

Figura 5 - Interface de configuração da regra

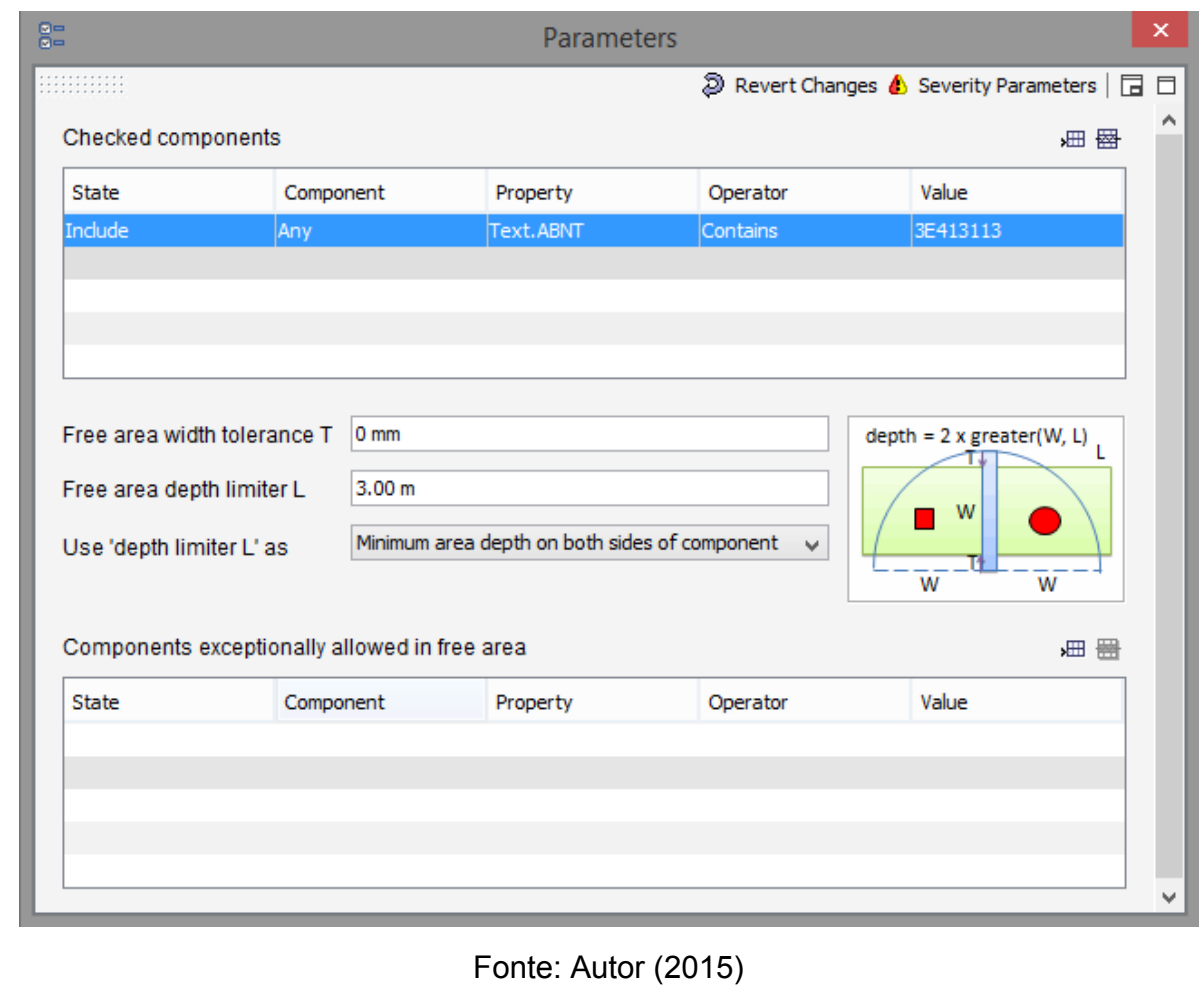

As regras apresentadas foram aplicadas a um projeto básico de estação metroferroviária que está em análise. A figura 6 ilustra um caso de não atendimento da regra 2.

A transição do projeto tradicional para o projeto em BIM cria novos processos e novas necessidades, como a inclusão de informação do código de classificação nos componentes 
e não apenas em tabelas. Esta necessidade requer uma quebra de barreira cultural maior do que o desenvolvimento do próprio projeto, que já é bem comum aos projetistas.

Figura 6 - Vista indicando o não atendimento da regra 2 executada no SMC.

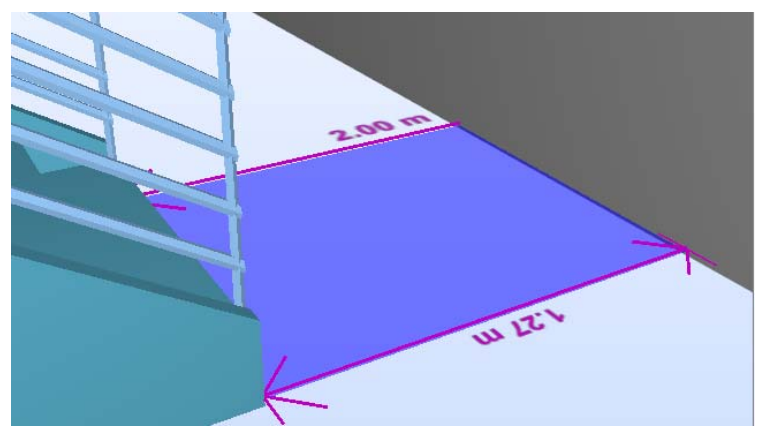

Fonte: Autor (2015)

\section{CONCLUSÃO}

O BIM está em constante crescimento de adoção pela indústria da construção, resultando em novos usos e processos devido a riqueza de informação presente. O profissional de análise, seja arquiteto ou engenheiro, que hoje atua de maneira manual e visual têm na Verificação de Regras um aliado adicionando velocidade e padronização do seu trabalho. A cultura existente no desenvolvimento de projeto civil atinge diretamente o BIM, é necessário revisá-la e planejar sua alteração, palestras, produção de documentos e treinamentos são ações desejáveis para que os novos processos e necessidades sejam introduzidas a realidade atual. Comum a toda mudança de cultura, a curva de aprendizado resultará em queda de produtividade neste momento inicial da adaptação para ambos, o projetista e o analista.

As regras aplicadas devem ser estudadas caso a caso, verificando as possibilidades de aplicações na plataforma definida e, verificando alterações necessárias na escrita para que seja mais facilmente aplicada a um computador. As regras aplicadas a uma plataforma permitem que seja analisado o projeto antes da entrega, e assim verificando previamente o que deve ser revisto. Desta forma a quantidade de comentários e revisões deverá ser diminuída. O planejamento de modelagem do projeto, assim como as informações contidas devem ser definidas no início do projeto, conforme indicado na criação de regras, sem estes padrões muitas regras poderão não ter resultado, e se houver será errôneo, portanto a padronização é um dos pontos principais nesta aplicação quando pensado em processo de análise, e é de responsabilidade do contratante ou de quem for aplicá-las o seu desenvolvimento.

O SMC acompanha uma biblioteca de regras pré-estabelecidas que permitem alterações de seus parâmetros. Este recurso facilita a aplicação e a permeabilidade para demais analistas, sendo este o principal motivo para a aplicação a esta plataforma. O estudo de caso apresentado continha regras de classe 1 e 2, conforme a classificação sugerida por Solihin (2015). Estas regras desenvolvidas e aplicadas ao projeto puderam demonstrar a importância da informação para a Verificação de Regras, já que a classificação de componentes é utilizada como o principal dado de identificação dos componentes, sendo esta informação adicionado pelo projetista.

A Verificação de Regras aplicada a etapa de análise de projeto libera o analista para focarse apenas nas não conformidades, resultando em uma maior dedicação a soluções. Assim, o uso Verificação de Regras atua como uma importante ferramenta de apoio ao profissional analista e projetista, e tem potencial para ser usado mais amplamente no futuro. 


\section{AGRADECIMENTOS}

O segundo autor agradece à FAPESP - Fundação de Amparo à Pesquisa do Estado de São Paulo e ao CNPq - Conselho Nacional de Desenvolvimento Científico e Tecnológico pelo apoio.

\section{REFERÊNCIAS}

ABNT. NBR 15965: sistema de classificação da informação da construção.Parte 3: Processos da construção. Rio de Janeiro: ABNT, 2011.

BUILDINGSMART. BCF intro. Disponível em: <http://www.buildingsmarttech.org/specifications/bcf-releases>. Acesso em: 11 jun. 2015.

EASTMAN, C. et al. Automatic rule-based checking of building designs. Automation in Construction, v. 18, n. 8, p. 1011-1033, 2009.

HAN, C. S.; KUNZ, J. C.; LAW, K. H. Client/Server Framework for On-Line Building Code Checking. Journal of Computing in Civil Engineering, v. 12, n. 4, p. 181-194, 1998.

HIETANEN, J. IFC model view definition format. International Alliance for Interoperability, Helsinki, 29 p., 2008. Disponível em: <http://www.buildingsmart-tech.org/ downloads/accompanying-documents/formats/mvdxml-documentation/MVD_Format_V2_ Proposal_080128.pdf>. Acesso em: 7 ago. 2015.

KHEMLANI, L. CORENET e-PlanCheck: Singapore's automated code checking system. 2005.

Level of Development Specification. [s.l: s.n.].

NAWARI, N. The Challenge of Computerizing Building Codes in a BIM Environment. Computing in Civil Engineering (2012), v. 1, p. 285-292, 11 jun. 2012a.

NAWARI, N. O. BIM-Model Checking in Building Design. Structures Congress 2012, p. 941-952, 29 mar. 2012b.

PENNSYLVANIA STATE UNIVERSITY. Building Information Modeling Project Execution Planning Guide 2.1. 2012.

SOLIHIN, W.; EASTMAN, C. Classification of rules for automated BIM rule checking development. Automation in Construction, v. 53, p. 69-82, 2015. 